\title{
PSEUDOTUMORAL PRESENTATION OF NEURO-BEHÇET DISEASE: A CONFUSING DIAGNOSIS
}

\author{
MOUNA SNOUSSI*, FATEN FRIKHA, SAMEH MARZOUK, ZOUHIR BAHLOUL
}

Department of Internal Medicine, Hedi Chaker Hospital, Sfax, Tunisia. Email: mounasnoussi23@yahoo.fr

Received: 1 December 2020, Revised and Accepted: 24 March 2021

ABSTRACT

A 35-year-old man was referred to the internal medicine department for acute hemiplegia with oral aphthous ulcers. The patient reported recurrent oral and genital ulcers more than 3 times a year. He also experienced one episode of peripheral thrombosis 1 year ago. The physical examination showed left hemiparesis with positive Babinski sign, hyperreflexia, and pseudofolliculitis in legs and trunk. The pathergy test was positive. Cerebral MRI showed a large mass hyperintense in T2 sequence in the regions of basal ganglia and corpus callosum with peripheral contrast enhancement and intensive edema around the lesion. The diagnosis of pseudotumoral neuro-Behçet disease was made on the basis of clinical history, the cerebral MRI result, and the exclusion of other tumoral and infectious diseases. The patient was treated with corticosteroids and cyclophosphamide with favorable outcome.

Keywords: Behçet disease, Brain tumor, Neurological manifestation.

(C) 2021 The Authors. Published by Innovare Academic Sciences Pvt Ltd. This is an open access article under the CC BY license (http://creativecommons. org/licenses/by/4.0/) DOI: http://dx.doi.org/10.22159/ijms.2021v9i3.40403. Journal homepage: https://innovareacademics.in/journals/index.php/ijms

\section{CASE REPORT}

A 35-year-old man was referred to the internal medicine department for acute hemiplegia with oral aphthous ulcers. He has no hypertension, diabetes, or hyperlipidemia and he does not smoke nor he drinks. The patient reported recurrent oral and genital ulcers more than 3 times a year. He also experienced one episode of peripheral thrombosis 1 year ago. The physical examination showed left hemiparesis with positive Babinski sign, hyperreflexia, and pseudofolliculitis in legs and trunk. The pathergy test was positive. There were no abnormal findings in complete blood counts, other blood tests including glycemia, lipid analysis, erythrocyte sedimentation rate, and C-reactive protein were normal. Cerebral MRI showed T2 flair hyperintense lesions in the regions of basal ganglia and corpus callosum with peripheral contrast enhancement and intensive edema around the lesion (Fig. 1). Differential diagnoses such as tuberculosis, syphilis, HIV infection, toxoplasmosis infection, lymphoma, and solid tumor were excluded by appropriate clinical, biological, and imaging testing. On the basis of previous clinical and preclinical findings, the diagnosis of pseudotumoral form of NBD was made. The patient was treated with high dose of corticosteroids initiated with three pulses of methylprednisolone and cyclophosphamide $1 \mathrm{~g} /$ month during 1 year then $1 \mathrm{~g}$ per 3 months during the $2^{\text {nd }}$ year. Favorable clinical and radiological outcomes were obtained within 2 years (Fig. 2).

\section{DISCUSSION}

Neurological involvements are one of the most serious manifestations of Behçet disease (BD) [1]. It includes parenchymal and non-parenchymal form which is more rare and includes cerebral vein thrombosis and arterial aneurysms [2]. Diagnosis of neuro-Behçet disease (NBD) may be difficult when it is the presenting sign or the unique feature of the disease. Parenchymal involvement is characterized by focal lesions, mainly in the brainstem, basal ganglia, diencephalic structures, and internal capsules [3]. The pseudotumoral form of NBD has been rarely reported and increases the difficulties of diagnosis. The prevalence of pseudotumoral NBD is estimated at 1.8\% [2]. In the literature, this entity was often inaugural of BD. Patients with pseudotumoral form of NBD have a higher Rankin's score at diagnosis, more frequent motor involvement and less frequent brainstem signs in comparison with non-pseudotumoral form [4]. Brain MRI is the suitable tools to diagnose this parenchymal type of NBD and confirms the presence of large intracerebral lesion located often in capsulothalamic, but may be cortical. Classical NBD differs from the pseudotumoral form of NBD by
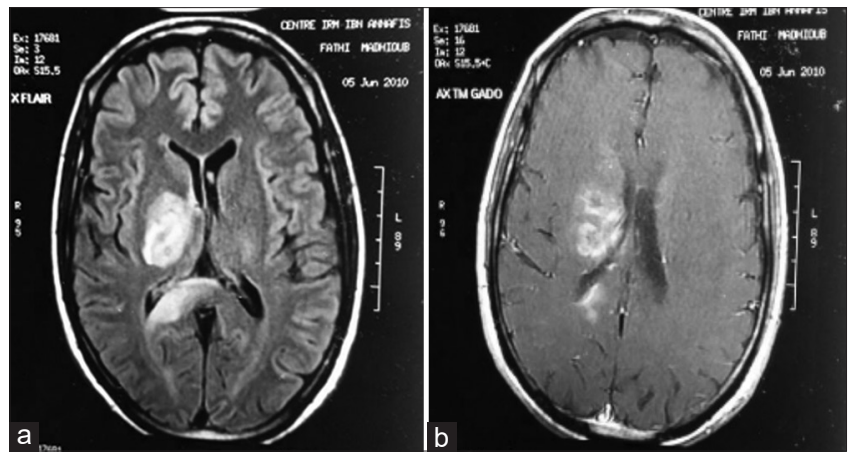

Fig. 1: (a) Axial T2-FLAIR sequence showing large hyperintense lesions in the regions of basal ganglia and corpus callosum.

(b) T1-weighted sequence with gadolinium injection revealing peripheral contrast enhancement of lesions

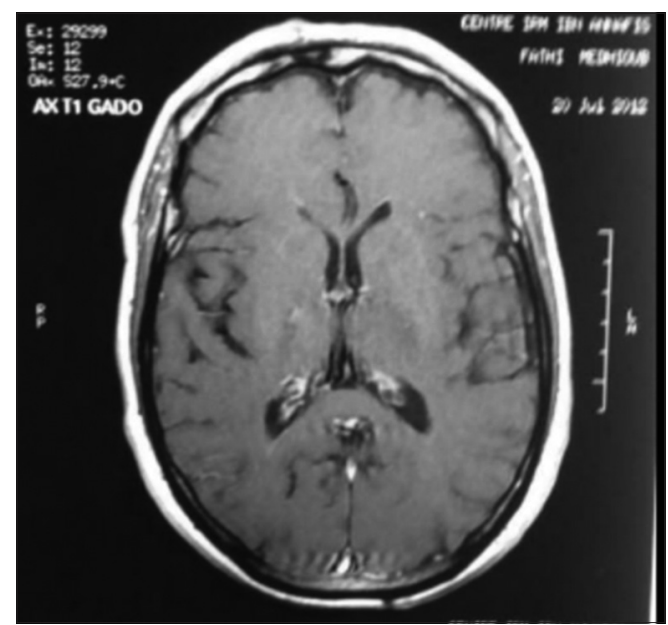

Fig. 2: T1-weighted sequence with gadolinium injection showing the disappearance of the radiological lesions after treatment 
the presence of a small lesions in the brainstem and mesodiencephalic junction [4,5]. Differential diagnoses of pseudotumoral form of NBD include infectious lesions, lymphoma, cerebral glioblastoma, and rarely inflammatory condition. Histological examination should be performed in case of difficulty of diagnosis and the absence of extra-neurological signs of BD [4]. The present case shows that in spite of its severe presentation, early aggressive intervention with corticosteroids and cytotoxic agents is effective in pseudotumoral form of NBD [4].

\section{REFERENCES}

1. Siva A, Kantarci OH, Saip S, Altintas A, Hamuryudan V, Islak C, et al Behcet's disease: Diagnostic and prognostic aspects of neurological involvement. J Neurol 2001;248:95-103

2. Noel N, Drier A, Wechsler B, Piettea J-C, De Paz R, Dormont D, et al. Neurological manifestations of Behcet's disease. Rev Med Interne 2013;35:112-20.

3. Serdaroğlu P. Behcet's disease and the nervous system. J Neurol 1998;245:197-205.

4. Noel N, Hutie M, Wechsler B, Vignes S, Huong-Boutin DL, Amoura Z, et al. Pseudotumoural presentation of neuro-Behcet's disease: Case series and review of literature. Rheumatology (Oxford) 2012;51:1216-25.

5. Koçer N, Islak C, Siva A, Saip S, Akman C, Kantarci O, et al. CNS involvement in neuro-Behcet syndrome: An MR study. AJNR Am J Neuroradiol 1999;20:1015-24. 